Pesq. Vet. Bras. 36(9):881-892, setembro 2016 DOI: 10.1590/S0100-736X2016000900015

\title{
Morfologia e histoquímica das glândulas sexuais acessórịas de Metachirus nudicaudatus, Didelphidae-Marsupialia
}

\begin{abstract}
Suely F. Costa ${ }^{2 *}$, José C. Nogueira ${ }^{3}$, Márcio G. Zangeronimo ${ }^{2}$, Bruno A. Soares ${ }^{4}$, Amália S. Chaves ${ }^{5}$ e Leandra Q. de Melo $^{2}$

ABSTRACT.- Costa S.F., Nogueira J.C., Zangeronimo M.G., Soares B.A., Chaves A.S. \& Melo L.Q. 2016. [Morphology and histochemistry of accessory sex glands of Metachirus nudicaudatus, Didelphidae-Marsupialia.] Morfologia e histoquímica das glândulas sexuais acessórias de Metachirus nudicaudatus, Didelphidae-Marsupialia. Pesquisa Veterinária Brasileira 36(9):881-892. Departamento de Medicina Veterinária, Universidade Federal de Lavras, Campus Universitário, Lavras, MG 37200-000, Brazil. E-mail: sfcosta@dmv.ufla.br

This paper describes the morphology and distribution of glycogen and mucous substances in the prostate and the bulbourethral glands of Metachirus nudicaudatus (Geoffroy, 1803), the only species of the genus. The prostate is surrounded by the tunica adventitia, and muscle and stroma is formed by connective urethral mucosa. The glandular parenchyma consists of secretory tubules, scattered throughout the connective tissue of the urethral mucosa which differs histologically and histochemically in cranial, middle, and caudal segments of the prostate. These morpho-histochemical differences are also observed in the outer, middle and inner parts of the tubular epithelium of each prostatic segment. In general, prostatic segments secrete neutral mucous substances, and the caudal segment also produces glycogen. The three pairs of bulbourethral glands (lateral, intermediate and medial) are surrounded by a capsule of dense connective tissue and skeletal striated muscle. The glandular parenchyma is formed by tubules or branched tubuloacinar, covered by simple epithelium which is characteristic for each pair of glands. The lateral bulbourethral glands and the medial bulbourethral glands produce neutral mucous substances and the secretion of the intermediate bulbourethral glands consists of neutral mucous substances, carboxylated acids, and sulfated acids. The M. nudicaudatus does not have ampullary glan$\mathrm{ds}$, seminal vesicles or coagulating glands.
\end{abstract}

INDEX TERMS: Morphology, histochemistry, accessory sex glands, jupati, Metachirus nudicaudatus, Didelphidae, Marsupialia, glycogen, mucous substances.

RESUMO.- São descritas a morfologia e a distribuição de glicogênio e mucossubstâncias na próstata e nas glândulas bulbouretrais de Metachirus nudicaudatus (Geoffroy,

\footnotetext{
${ }^{1}$ Recebido em 27 de fevereiro de 2016.

Aceito para publicação em 22 de maio de 2016

${ }^{2}$ Departamento de Medicina Veterinária, Universidade Federal de Lavras (UFLA), Campus UFLA, Lavras, MG 37200-000, Brasil. *Autor para correspondência: sfcosta@dmv.ufla.br

${ }^{3}$ Setor de Morfologia, Instituto de Ciências Biológicas, Universidade Federal de Minas Gerais (UFMG), Av. Presidente Antônio Carlos 6621, Pampulha, Belo Horizonte, MG 31270-901, Brasil.

${ }^{4}$ Laboratório de Doenças das Aves, Escola de Veterinária (EV), UFMG, Av. Presidente Antônio Carlos 6627, Campus Pampulha, Belo Horizonte, MG 31270-901.

${ }^{5}$ Instituto de Ciências Agrárias (ICA), UFMG, Campus Regional de Montes Claros, Avenida Universitária 1.000, Bairro Universitário, Montes Claros, MG 39404-547, Brasil.
}

1803), única espécie do gênero. A próstata é envolvida pelas túnicas adventícia e muscular, e o estroma é formado pelo conjuntivo da mucosa uretral. 0 parênquima é constituído pelos túbulos secretores, disseminados na mucosa uretral, e que diferem histológica e histoquimicamente nos segmentos cranial, médio e caudal. Essas diferenças morfo-histoquímicas também são observadas nas partes externa, média e interna de cada túbulo. De um modo geral, os três segmentos prostáticos secretam mucossubstâncias neutras, porém o segmento caudal produz também glicogênio. Os três pares de glândulas bulbouretrais (laterais, intermédias e mediais) do Metachirus são envolvidas por uma cápsula conjuntiva e músculo estriado esquelético. 0 maior par é a bulbouretral lateral que é constituída por longos túbulos secretores de mucossubstâncias neutras. As bulbouretrais intermédias são formadas por túbulos rami- 
ficados, que produzem mucossubstâncias neutras, ácidas carboxiladas e ácidas sulfatadas. Os túbulo-ácinos ramificados das bulbouretrais mediais secretam mucossubstâncias neutras. O Metachirus não possui glândulas ampulares, vesículas seminais nem glândulas de coagulação.

TERMOS DE INDEXAÇÃO: Morfologia, histoquímica, glândulas sexuais acessórias, jupati, Metachirus nudicaudatus, Didelphidae, Marsupialia, glicogênio, mucossubstâncias.

\section{INTRODUÇÃO}

Os mamíferos das subclasses Metatheria e Eutheria são estreitamente relacionados, mas tiveram o curso evolutivo separado desde o início do Cretáceo. A distinção entre as duas subclasses é primariamente reprodutiva, refletindo a evolução de estratégias alternativas para a viviparidade e a lactação. As espécies de marsupiais (Metatherios) existentes caracterizam-se pelos seus curtos períodos de gestação, pelo pouco desenvolvimento embrionário dos filhotes ao nascimento, e em muitos, por possuírem uma bolsa de proteção, o marsúpio. Esta bolsa é uma prega da pele situada na parte caudal e ventral do abdome, recobrindo as glândulas mamárias. Para os marsupiais, a lactação é o modo dominante de transferência de energia para o filhote. As diferenças entre os padrões reprodutivos dos Metatherios e dos Eutherios refletem respostas evolutivas diferentes às pressões do ambiente (Tyndale-Biscoe 1973, Renfree 1981).

O estudo da biologia reprodutiva dos marsupiais implica no conhecimento de parâmetros morfológicos tanto dos órgãos genitais femininos como masculinos. Sobre os órgãos genitais masculinos de marsupiais, um dos primeiros estudos foi realizado no gambá por Cowper (1704), que o comparou com os órgãos genitais femininos já conhecidos e descreveu as diferenças anatômicas encontradas. Pertencentes à ordem Didelphimorphia, os marsupiais brasileiros compreendem um diversificado grupo de espécies de pequeno porte, incluindo atualmente 15 gêneros e 56 espécies. A família Didelphidae constitui o grupo mais versátil, com 63 espécies viventes (Gardner, 1993), incluídas em 15 gêneros dos quais pouco se conhece sobre a morfologia dos órgãos genitais masculinos.

0 gênero Metachirus possui uma única espécie, o Jupati, Metachirus nudicaudatus (Geoffroy 1803). Trata-se de um marsupial de hábitos noturnos, terrestre e com ampla distribuição na América do Sul, sendo encontrado em quase todo o Brasil, em locais de florestas densas e campos arbustivos. Estudos sobre a morfologia dos órgãos genitais de $M$. nudicaudatus foram realizados por Costa et al. $(1994,1996$, 2015), Costa (1995), Cruz et al. (2011a, 2011b). Entretanto, pouco se sabe sobre a morfologia e a natureza das secreções prostática e das glândulas bulbouretrais do Jupati.

Em marsupiais americanos já estudados a próstata é bem desenvolvida, do tipo disseminada e possui três segmentos distintos (cranial, médio e caudal), em cor, diâmetro e extensão (Chase 1939, Ribeiro1981, Martan 1983, Garcia \& Gonçalves 1984, Martinelli 1990, Costa 1995, 1996, Carvalho 1996, Barros et al. 2003, Lima 2013). Devido às diferenças de segmentação da próstata entre marsupiais americanos e australianos (Rodger \& Hughes 1973, Dawson et al. 1988), tornou-se difícil comparar os segmentos prostáticos entre os dois grupos. De acordo com Rodger \& Hughes (1973) e Temple-Smith (1984), mucossubstâncias neutras ou ácidas são os principais tipos de secreção prostática em espécies australianas. A presença de mucossubstâncias neutras e ácidas, glicogênio e proteínas na próstata é registrada em espécies de marsupiais da família Didelphidae já estudados, havendo diferenças, entre as espécies, com relação ao teor e ao local de produção destas substâncias (Hruban et al. 1965, Martan \& Allen 1965, Ribeiro 1981, Martan 1983, Garcia \& Gonçalves 1984, Nogueira et al. 1984, Nogueira et al. 1985, Ribeiro \& Nogueira 1985, Martinelli et al. 1991, Costa 1995, Carvalho 1996).

A presença de dois ou três pares de glândulas bulbouretrais na maioria dos marsupiais e a composição complexa e heterogênea de suas secreções sugere papel importante dessas glândulas na fisiologia reprodutiva desses animais. (Martan 1983, Nogueira et al. 1984, Martinelli et al. 1991, Costa 1995, Costa et al. 1996, Carvalho 1996, Barros et al. 2003, Lima 2013). Embora haja variações qualitativas no teor das secreções destas glândulas, mucossubstâncias neutras e mucossubstâncias ácidas carboxiladas e sulfatadas, além de glicogênio, têm sido detectados em vários marsupiais brasileiros (Ribeiro 1981, Nogueira et al. 1984, Ribeiro \& Nogueira 1985, Martinelli 1990, Martinelli et al. 1991, Costa 1995, Carvalho 1996).

Visando a contribuir para os estudos da biologia da reprodução de marsupiais brasileiros e considerando a existência de poucos trabalhos sobre as glândulas sexuais acessórias de marsupiais americanos,no presente trabalho encontra-se uma descrição da morfologia da próstata e das glândulas bulbouretrais de Metachirus nudicaudatus, bem como a detecção histoquímica de glicogênio e mucossubstâncias.

\section{MATERIAL E MÉTODOS}

Foram utilizadas as glândulas sexuais acessórias de cinco $\mathrm{Me}$ tachirus nudicaudatus machos, adultos em fase reprodutiva, capturados no município de Linhares/ES, Brasil (autorização 002/93-DEVIS; 008/95 DEVIS IBAMA). Para estudo histológico e histoquímico, fragmentos da próstata e das glândulas bulbouretrais foram fixados em líquido de Bouin durante 24 horas, conforme a técnica de Lillie \& Fullmer (1976). 0 material fixado foi desidratado em série crescente de álcool etílico, infiltrado e incluído em resina Technovit 7100 - Kulzer, Hidroxietilmetacrilato (Chiarini-Garcia 1991). Alguns fragmentos desse material foram desidratados, diafanizados em xilol, infiltrados e incluídos em parafinas segundo a técnica de rotina (Luna 1968). Os blocos de resina foram cortados em micrótomo Reichert-Jung (cortes de cinco $\mu \mathrm{m}$ ), e os de parafina em micrótomo Spencer (American Optical Company), obtendo-se cortes de sete $\mu \mathrm{m}$ de espessura. Para estudo histológico das diferentes glândulas, foram utilizadas as colorações Hematoxilina-Eosina (HE), coloração para fibras elásticas (Nogueira \& Ribeiro 1980) e impregnaçäo argêntica para fibras reticulares (Gomori 1937).

Para histoquímica de glicogênio e mucossubstâncias foram usados os seguintes métodos: Ácido Periódico-Reativo de Schiff (PAS), segundo McManus (1946); digestão pela amilase salivar, seguida de PAS (Lison 1960); Alcian-Blue (AB) pH 2,5 (Mowry 1956); Alcian-Blue (AB) pH 1,0 (Lev \&Spicer 1964); Alcian-Blue (AB) pH 2,5, seguido de PAS (Mowry 1956, Lison 1960); Ninhidrina-Schiff (Yasuma \& Ichikawa 1953); bloqueio da reação da 
Ninhidrina-Schiff pelo ácido nitroso (Lillie 1958). As preparações realizadas no material incluído em resina seguiram as indicações de Chiarini-Garcia (1991).

\section{RESULTADOS}

As glândulas sexuais acessórias de Metachirus nudicaudatus são a próstata e três pares de glândulas bulbouretrais. A próstata é bem desenvolvida, apresenta uma forma de "ponto de interrogação" e possui três segmentos distintos em cor e tamanho. 0 segmento cranial é de coloração rósea, o médio é maior, apresentando cor brancoleitosa, e o caudal cor cinza. Os três pares de glândulas bulbouretrais, laterais (BUL), intermédias (BUI) e mediais (BUM), situam-se na raiz do pênis. As BUL são mais volumosas e situadas entre os músculos bulbo-esponjoso (BS) e ísquiocavernoso (IC). As BUI situam-se caudomedialmente às BUL e dorsalmente encaixadas na depressão do músculo IC. As BUM são menores e situam-se entre a borda posterior da BUI e a uretra membranosa. Os ductos excretores dessas glândulas desembocam na uretra peniana. 0 M. nudicaudatus não possui glândulas ampulares, vesículas seminais nem glândulas de coagulação (Fig.1).

A próstata é constituída por numerosas glândulas tubulares compostas, disseminadas no tecido conjuntivo da mucosa uretral (Fig.2). Os túbulos dispõem-se radialmente ao lume da uretra e desembocam no mesmo através de numerosos ductos coletores. A glândula é envolvida pelas túnicas adventícia e muscular. A túnica adventícia é formada por tecido conjuntivo fibroso, vasos sanguíneos e linfáticos e nervos. Gânglios nervosos viscerais também são observados. 0 estroma glandular prostático é formado pelo tecido conjuntivo da mucosa uretral, sendo escasso entre os túbulos glandulares e abundante, à medida que se aproxima do lume uretral, entre os ductos coletores. Fibras colágenas, muscu- lares lisas e elásticas são frequentes no conjuntivo uretral. As fibras reticulares formam uma delicada trama ao redor dos túbulos glandulares (Fig.3E,F). 0 parênquima glandular

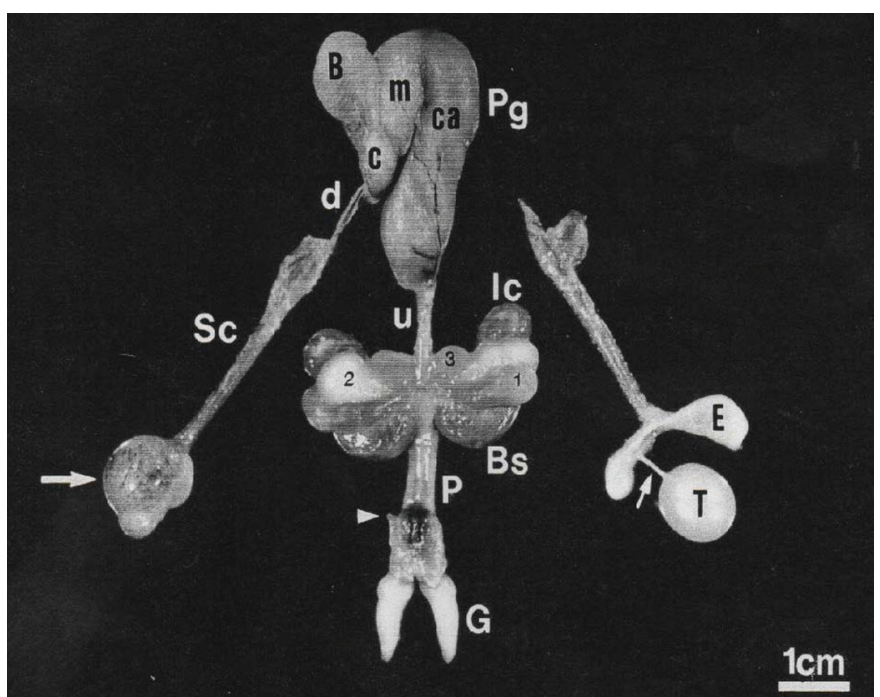

Fig.1. A figura mostra os órgãos genitais masculino de Metachirus nudicaudatus dissecado e com pênis não distendido. T = testículo, $\mathrm{E}=$ epidídimo retirados da túnica vaginal. A seta menor indica o pedículo testículo-epididimário. A seta maior, no lado oposto, mostra os dois órgãos envolvidos pela túnica vaginal. $\mathrm{Sc}=$ funículo espermático; $\mathrm{d}$ = parte abdominal do ducto deferente; $\mathrm{B}=$ bexiga; Pg = próstata, mostrando seus três segmentos: $\mathrm{c}=$ cranial, $\mathrm{m}=$ médio, $\mathrm{ca}=$ caudal; $\mathrm{u}=$ uretra membranosa; 1 = glândulas bulbo - uretrais laterais; 2 = glândulas bulbo-uretrais intermédias; 3 = glândulas bulbo-uretrais mediais; Ic = músculos ísquio-cavernosos; Bs = músculos bulbo-esponjosos; $\mathrm{P}$ = corpo peniano; $\mathrm{G}$ = glande bífida. $\mathrm{A}$ cabeça da seta mostra a inserção dos músculos retratores do pênis na parte dorsal da flexura sigmóide.

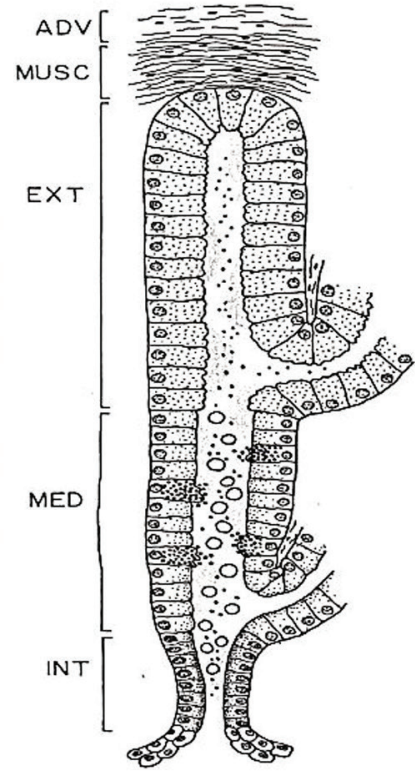

SEG. CRANIAL
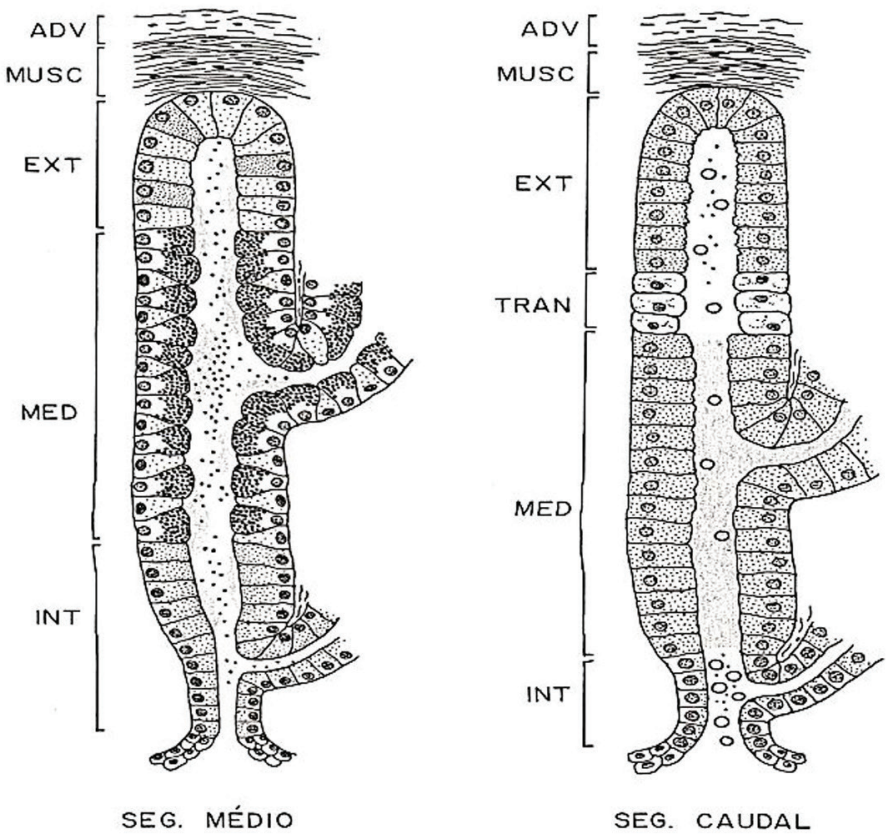

Fig.2. Desenho esquemático dos diferentes segmentos da próstata mostrando os diferentes tipos celulares de cada segmento. ADV = adventícia; MUSC = camada muscular; EXT = parte externa; $\mathrm{MED}$ = parte média; INT = parte interna. 
é constituído pelos túbulos secretores que diferem histológica e histoquimicamente nos segmentos cranial, médio e caudal da próstata. Essas diferenças morfo-histoquímicas também são observadas nas partes externa, média e interna do epitélio tubular de cada segmento prostático (Fig.2). A parte externa é constituída pelos fundos dos túbulos e localiza-se logo abaixo da camada muscular uretral. A parte média é constituída pelas porções restantes do túbulo e a interna é formada pelos ductos coletores, que se unem uns aos outros antes de desembocarem no lume uretral (Fig.2).

A parte externa do túbulo glandular no segmento cranial possui um epitélio simples colunar e com numerosas projeções apicais. As células epiteliais são acidófilas, com núcleos esféricos, vesiculosos com nucléolo evidente, localizados na parte basal. 0 lume é estreito, com poucos corpos de secreção acidófilos no seu interior. Frequentemente observam-se as fusões de túbulos adjacentes (Fig.2 e 3A). A reação PAS positiva é observada em pequenas granulações e nas projeções apicais. Essa reação permaneceu inalterada após o tratamento com amilase-salivar. Pela Ninhidrina-Schiff, as células coram-se fracamente em toda a sua extensão, tornando-se negativas após o bloqueio pelo ácido nitroso. A alcianofilia é negativa na parte externa (Quadro 1). A parte média apresenta epitélio simples colunar. A
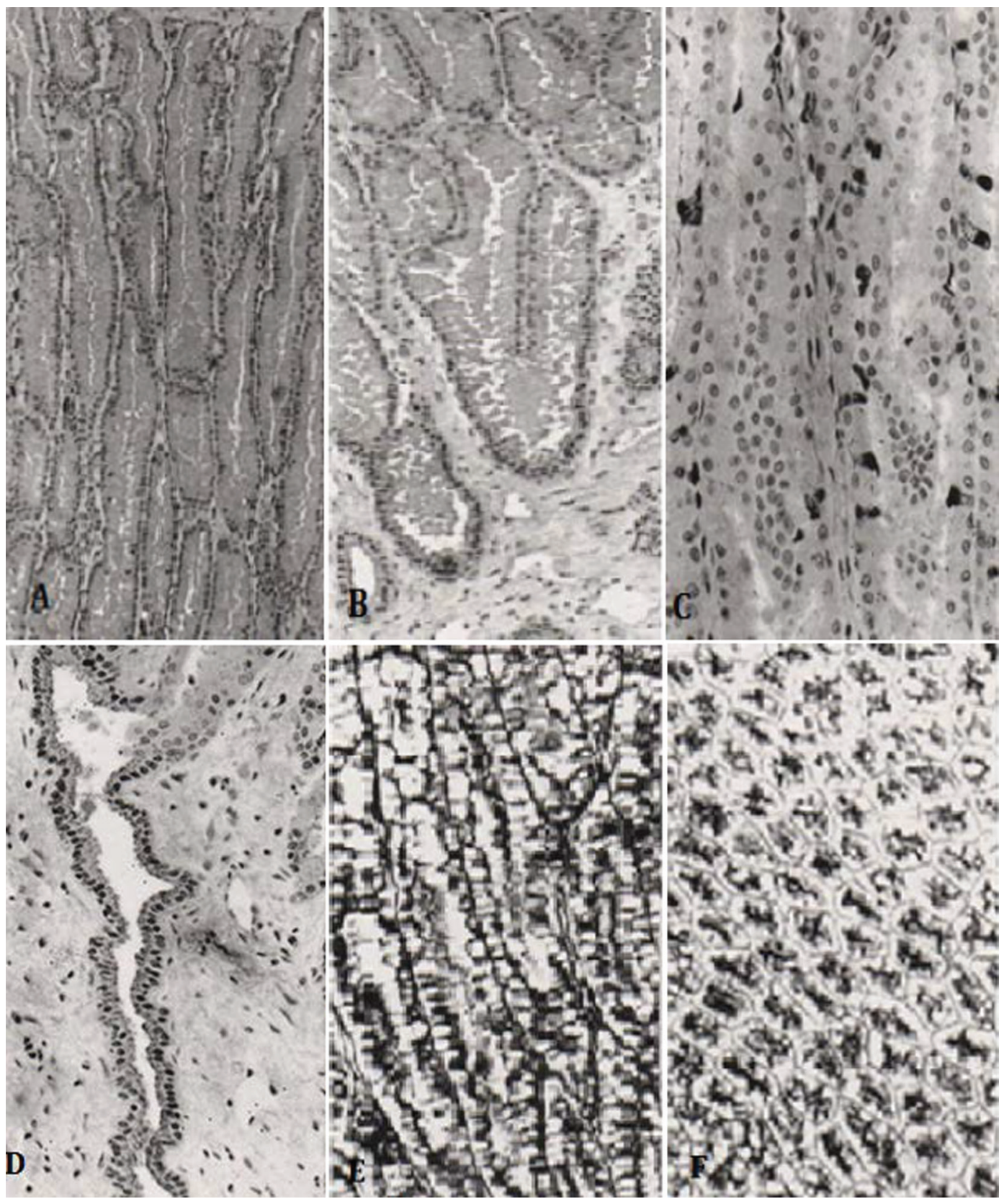

Fig.3. Próstata. (A) Partes externa e média do segmento cranial. (B) Partes média e interna do segmento cranial. HE, 76x. (C) Parte média do segmento cranial. Observam-se células com citoplasma PAS positivo. PAS + H, 76x. (D) A parte interna (ducto) da glândula do segmento cranial é formada por células contendo pequenas e numerosas granulações apicais PAS - positivas. PAS+H, 76x. (E) Fibras reticulares do estroma ao redor de túbulos glandulares em secções longitudinais. (F) Fibras reticulares do estroma ao redor de túbulos glandulares em secções transversais. Impregnação argêntica de Gomori, 76x. 
Quadro 1. Histoquímica de glicogênio e mucossubstâncias neutras na próstata e nas glândulas bulbouretrais de Metachirus nudicaudatus

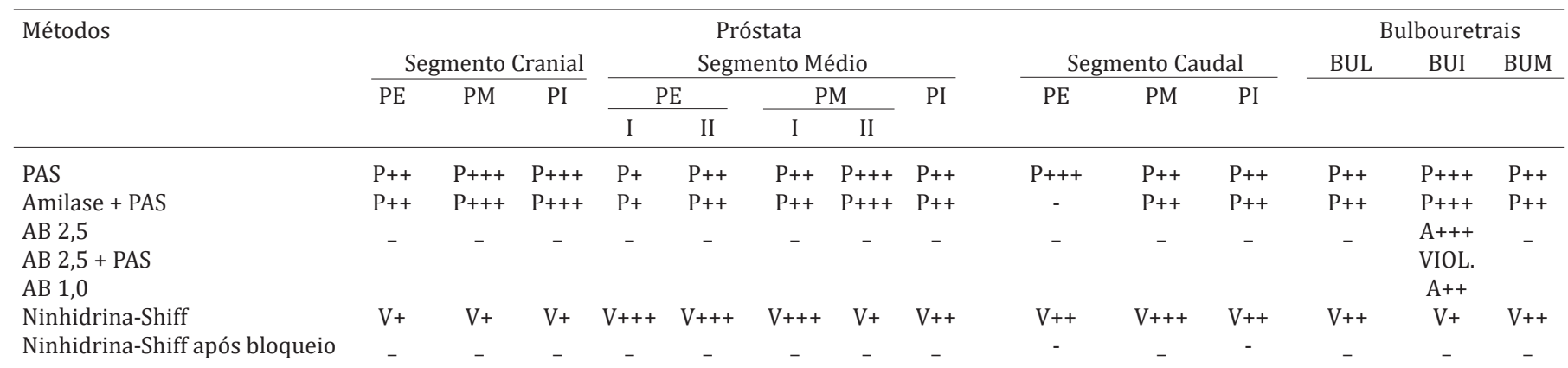

PE = Parte Externa; PM = Parte Média; PI = Parte Interna; BUL = Bulbouretral Lateral; BUI = Bulbouretral Intermédia; BUM = Bulbouretral Medial; I e II = Tipos Celulares; P = Púrpura; A = Azul; V = vermelho; VIOL. = Violeta; $(+)$ = reação fraca; $(++)$ = reação moderada; $(+++)$ reação forte; $(-)$ = reação negativa.

superfície é pouco irregular, sem projeções apicais desenvolvidas. As células epiteliais são acidófilas, com núcleos esféricos, vesiculosos, situados na base da célula. 0 lume é amplo e contem corpos de secreção acidófilos no seu interior (Fig.2 e 3A,B). Mastócitos são abundantes ao longo das partes externa e média dos túbulos. Grânulos fortemente PAS positivos são observados no citoplasma de algumas células (Fig.3C) e no lume glandular. Esses grânulos permanecem corados após tratamento com amilase-salivar. A maioria das células desta região possui pequenas granulações PAS positivas semelhantes às da parte externa. As células e os grânulos no lume apresentam-se fracamente corados pela Ninhidrina-Schiff, cuja reação tornou-se negativa após o bloqueio. A alcianofila é negativa (Quadro 1). A parte interna do túbulo (ductos coletores) apresenta epitélio simples cúbico (Fig. 2 e 3B) inicialmente, com células acidófilas. Ao nível da desembocadura na uretra, o epitélio é de transição, semelhante ao epitélio uretral. No lume são observados corpos de secreção acidófilos (Fig.3B). Observa-se grande quantidade de tecido conjuntivo entre os túbulos nessa parte da glândula. Pequenas granulações apicais apresentam-se fortemente coradas pelo PAS (Fig.3D), permanecendo coradas após digestão pela amilase-salivar. Pela Ninhidrina-Schiff, as células apresentam-se fracamente coradas, bem como os corpos de secreção. A reação tornou-se negativa após o bloqueio pelo ácido nitroso. A alcianofilia permanece negativa (Quadro 1).

No segmento médio a parte externa é a menor do túbulo e apresenta epitélio simples colunar (Fig.2 e 4A). As células epiteliais possuem núcleo achatado e citoplasma apresenta-se pouco corado com granulações basófilas. Dois tipos celulares foram observados, sendo que o tipo predominante apresentou fraca reação PAS positiva, amilase-resistente, e o outro, moderada reação, também amilase-resistente (Fig.4C). Pela Ninhidrina-Schiff essa parte do túbulo foi a que mais se apresentou corada, tornando-se negativa após o bloqueio pelo ácido nitroso. A alcianofilia foi negativa (Quadro 1). A parte média ocupa a maior extensão do túbulo, observando-se com frequência a confluência entre os túbulos. Ela é formada por epitélio colunar com dois tipos celulares (Fig.2 e 4A,B). Um tipo celular com citoplasma levemente basófilo e homogêneo, núcleo esférico, basal e de cromatina densa; e o outro tipo possui granulações cito- plasmáticas grosseiras, núcleo ovóide e vesiculoso, situado no terço basal da célula. As reações ao PAS e à Ninhidrina-Schiff foram positivas nos dois tipos celulares. As células basófilas apresentaram um aspecto homogêneo ao PAS e com moderada reação positiva, porém coraram-se mais fortemente pela Ninhidrina-Schiff. 0 outro tipo celular apresentou granulações grosseiras, fortemente PAS positivas (Fig.4C-E) e uma fraca reação para Ninhidrina-Schiff. Nos dois tipos celulares a reação ao PAS foi resistente à amilase salivar. Após o bloqueio pelo ácido nitroso, as células tornaram-se negativas à Ninhidrina-Schiff. A alcianofilia foi negativa (Quadro 1).A parte interna do túbulo possui epitélio colunar inicialmente, modificando-se para cuboidal e do tipo transição próximo à desembocadura com a uretra. Esse epitélio possui finas granulações acidófilas citoplasmáticas (Fig.2 e 4B). As granulações coram-se pela Ninhidrina-Schiff e pelo PAS (Fig.4F).Após a digestão pela amilase, a PAS-positividade permaneceu, enquanto a reação pela Ninhidrina-Schiff tornou-se negativa após o bloqueio pelo ácido nitroso. A alcianofilia foi negativa (Quadro 1).

A parte externa do segmento caudal possui epitélio cuboidal com projeções apicais bem desenvolvidas, dando ao lume um aspecto franjado. As células são acidófilas e apresentam um aspecto finamente vacuolado (Fig.2 e 5A,C). A secreção acidófila, encontrada no lume, possui uma parte amorfa e outra granular (Fig. 5C). Na região de transição entre as partes externa e média, o epitélio apresenta uma faixa de células com vacúolos citoplasmáticos maiores (Fig.5A,C). As pequenas e numerosas granulações citoplasmáticas, fortemente PAS positivas (Fig.5E), foram removidas após a digestão pela amilase salivar, demonstrando-se, desse modo a presença de glicogênio nesse segmento glandular. Esse glicogênio também foi observado na região de transição entre as partes externa e média do túbulo (nas células de aspecto vacuolado). Após o tratamento com amilase salivar algumas células permaneceram difusa e fortemente coradas pelo PAS. Pela Ninhidrina-Schiff as células apresentaram reação positiva. Essa reação tornou-se negativa após o bloqueio pelo ácido nitroso. A alcinofilia foi também negativa nessa parte do túbulo (Quadro 1). A parte média possui epitélio cuboidal com células acidófilas e com projeções apicais. Após a região de transição, frequentemente observa-se a fusão de túbulos, o lume torna-se am- 
plo e repleto de secreção acidófila amorfa e sob a forma de glóbulos (Fig.2 e 5A,B). A moderada PAS-positividade, encontrada em poucas células, permaneceu inalterada após a digestão pela amilase salivar. As células e os grânulos do lume coram-se fortemente pela Ninhidrina-Schiff (Fig.5F). A reação tornou-se negativa após o bloqueio pelo ácido nitroso. A alcianofilia foi negativa (Quadro 1). 0 epitélio da parte interna é cuboidal, inicialmente, e de transição ao nível da desembocadura na uretra (Fig.2 e 5B,D). Na transição da parte média para a interna observa-se a confluência de túbulos com lume dilatado e o epitélio é baixo (Fig.5B). As células epiteliais são acidófilas e apresentam núcleo es- férico, vesiculoso com nucléolo evidente. Mastócitos são frequentemente observados no tecido conjuntivo entre os túbulos na parte interna. Células esparsas e a secreção no lume mantiveram a PAS- positividade mesmo após o tratamento com amilase salivar. A reação para Ninhidrina-Schiff também foi positiva nas células e na secreção. A alcianofilia foinegativa nessa parte glandular (Quadro 1).De um modo geral, os seg prostáticos secretam mucossubstâncias neutras, sendo que o segmento caudal também produz glicogênio.

A uretra prostática apresenta lume amplo e pregueado longitudinalmente, podendo conter secreção no seu inte-
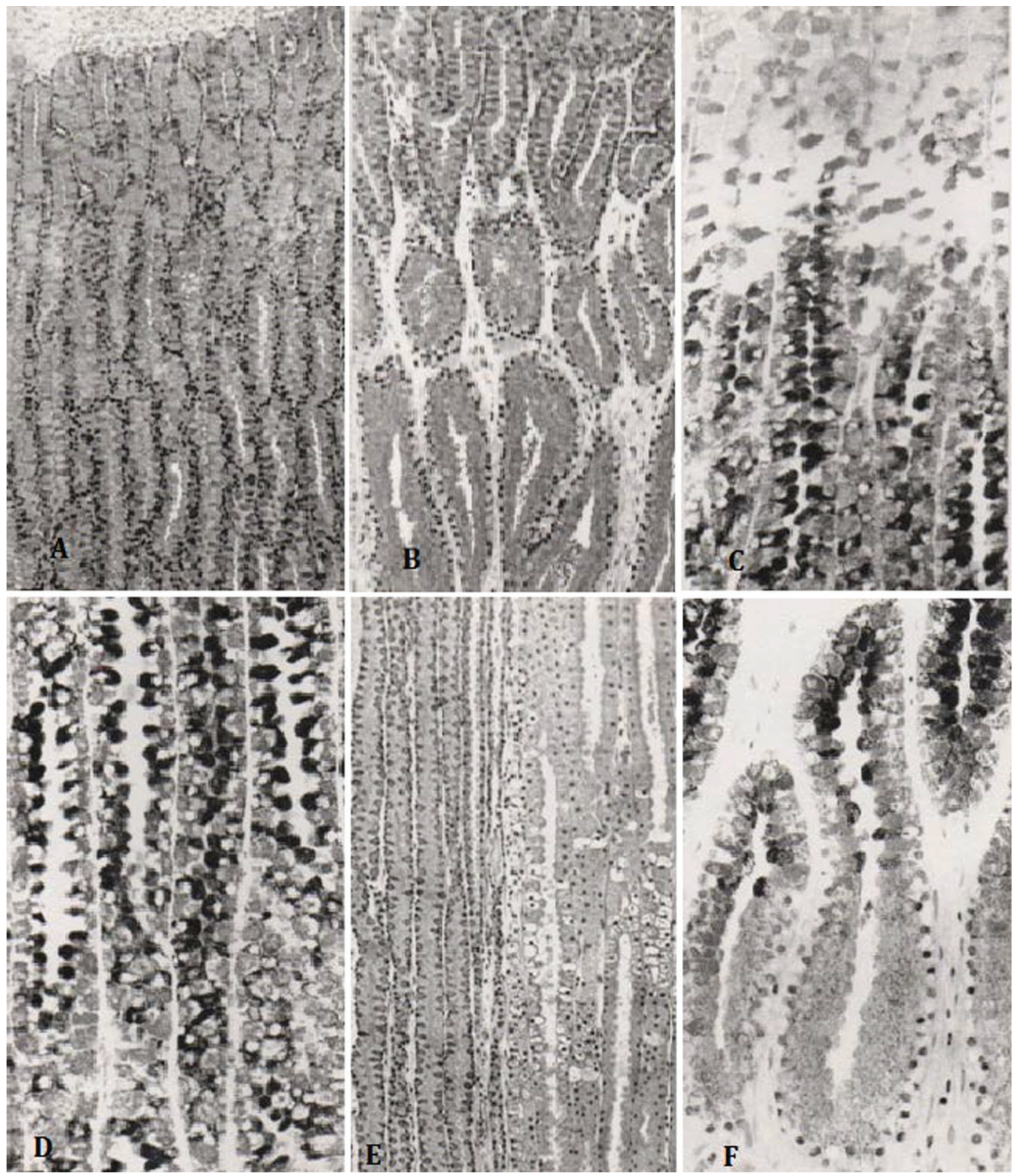

Fig.4. Próstata. (A) Partes externa e média do segmento médio. (B) Partes média e interna do segmento médio. HE, 76x. (C) A parte externa do segmento médio mostra dois tipos celulares frente à reação do PAS. (D) A figura mostra os dois tipos celulares da parte média do segmento médio. PAS+H, 76x. (E) Detalhe da transição do segmento médio para o caudal. Observar os dois tipos celulares da parte média do segmento médio (metade esquerda da foto) e o aspecto diferente do segmento caudal (metade direita da foto). HE, 76x. (F) Observar a progressiva transição da parte média para a interna do segmento médio. Na parte interna, observam-se numerosas e pequenas granulações PAS positiva no citoplasma. PAS+H, 76x. 

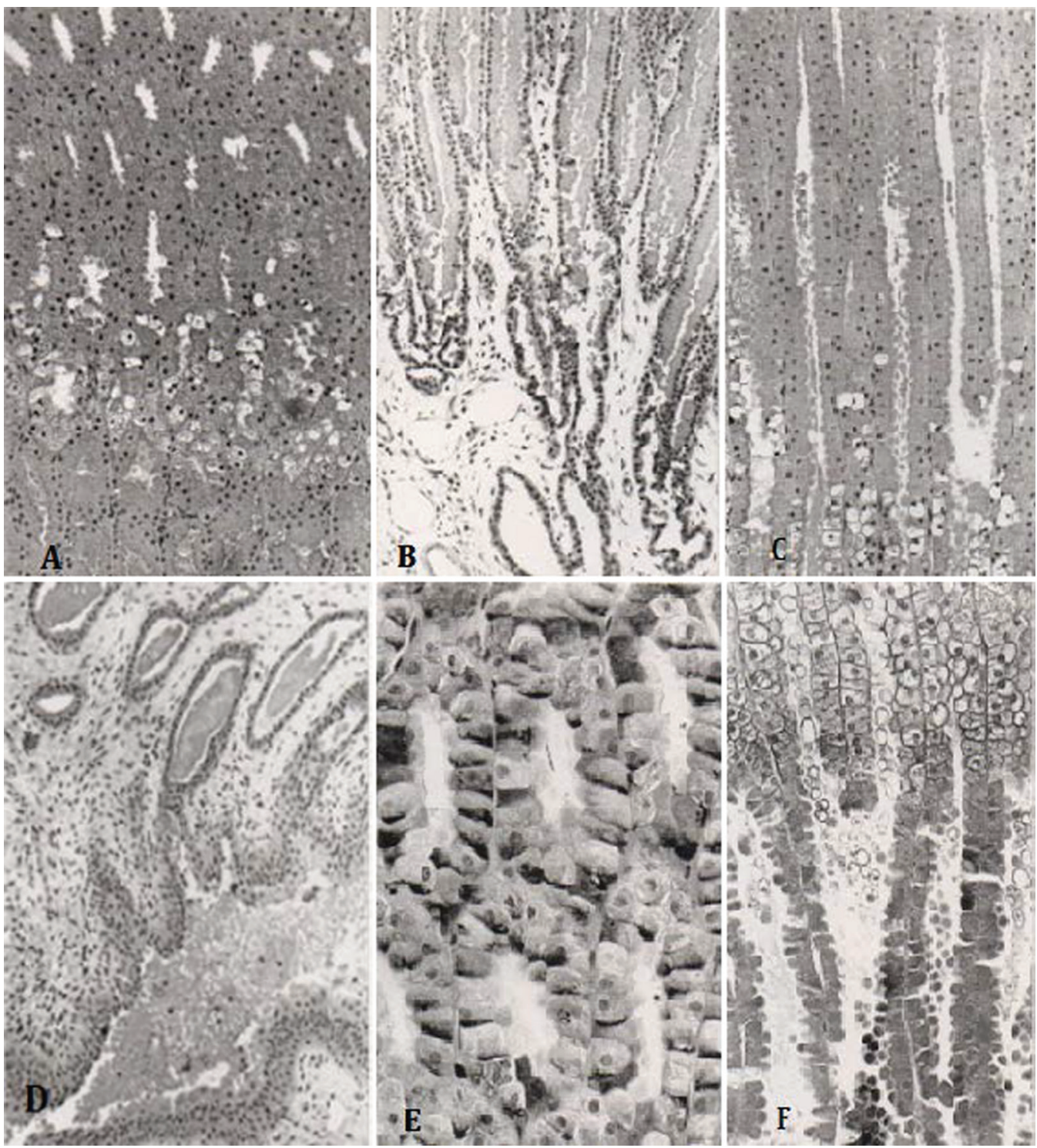

Fig.5. Próstata. (A) Partes externa e média do segmento caudal. Observar o aspecto vacuolado característico das células na região de transição entre essas partes. HE, 76x. (B) Partes média e interna do segmento caudal. HE, 76x. (C) Parte externa do segmento caudal. Observar a presença de glóbulos de secreção no lume do túbulo glandular. HE, 76x. (D) Uretra prostática. Ao nível do segmento caudal observar o pregueamento longitudinal da mucosa e o lume amplo repleto de secreção. HE, 76x. (E) A figura mostra a forte reação PAS positiva da parte externa do segmento caudal. PAS+H, 76x. (F) Observar a reação Ninhidrina-Schiff nas células e nos grânulos no lume da parte média do segmento caudal. Ninhidrina- Schiff, 76x.

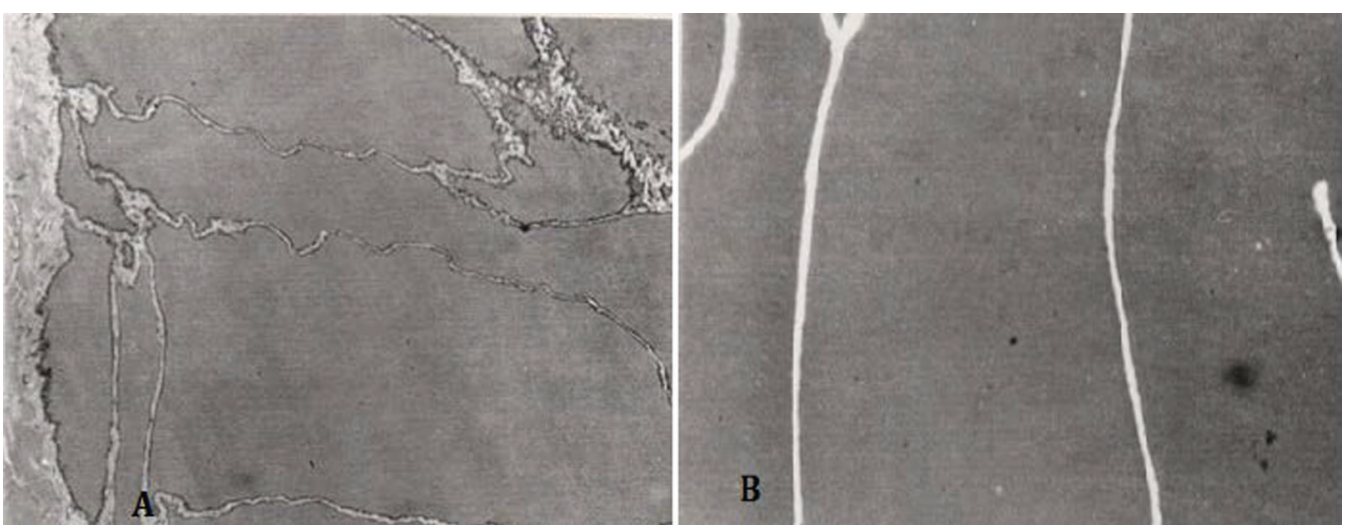

Fig.6. Glândula bulbouretral lateral. (A) Observar o aspecto expandido dos túbulos glandulares pelo acúmulo de secreção. HE, 76x. (B) Intensa reação PAS positiva na secreção contida no lume. PAS, 76x. 
rior (Fig.5D). A sua mucosa possui epitélio de transição e a lâmina própria é constituída de tecido conjuntivo frouxo, principalmente na camada subepitelial. Raros mastócitos são vistos na lâmina própria do segmento cranial, que aumentam em número nos segmentos médio e caudal. A mucosa é atravessada pelos ductos das numerosas glândulas prostáticas que desembocam no lume uretral ao longo de todo o seu trajeto. Pequenos vasos sanguíneos e linfáticos são vistos intercalados entre os ductos prostáticos. Esses vasos à medida que caminham para os segmentos médio e caudal, tornam-se mais calibrosos.

Os três pares de glândulas bulbouretrais (laterais, intermédias e mediais) apresentam-se envolvidas por uma cápsula de tecido conjuntivo denso, contendo vasos sanguíneos, nervos e pequenos acúmulos de células adiposas (Fig.1). Abaixo dessa cápsula, encontra-se uma espessa musculatura estriada esquelética. Subjacente à camada muscular há uma estreita faixa de tecido conjuntivo que penetra no interior da glândula. 0 estroma é constituído por tecido conjuntivo delicado na bulbouretral lateral (Fig.6A), sendo mais desenvolvido nas bulbouretrais intermédias (Fig.7B,D) e medial (Fig.8A). Uma trama de fibras reticulares envolve os adenômeros (Fig.7C e 8A). 0 parênquima glandular é formado por túbulos ou túbulo-ácinos ramifi-

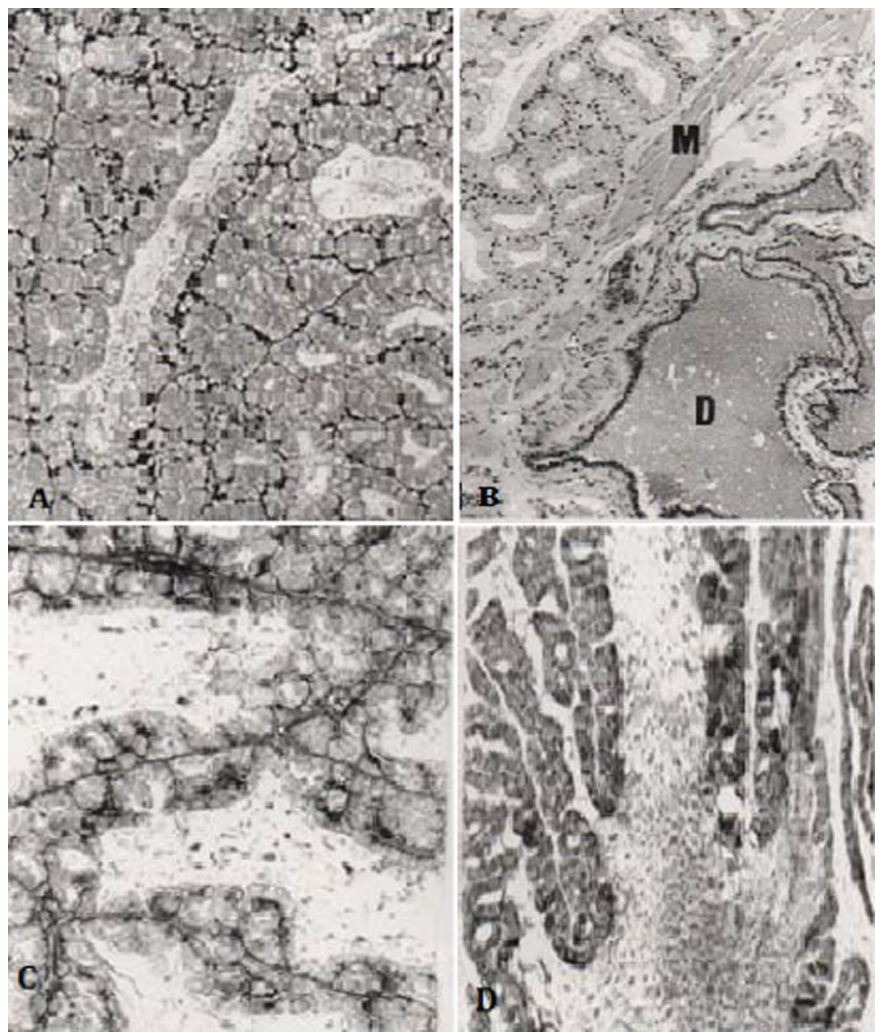

Fig.7. Glândula bulbouretral intermédia. (A) Túbulos glandulares seccionados transversal e longitudinalmente HE, 76x. (B) Túbulos glandulares separados do ducto principal (D) por feixes de fibras musculares estriadas esqueléticas (M). HE, 76x. (C) Delicadas fibras reticulares são observadas ao redor dos túbulos glandulares. Impregnação argêntica de Gomori, 192x. (D)Túbulos glandulares convergindo para formar um espaço coletor contendo secreção heterogênea no lume. AB pH 2,5+PAS, 192x.

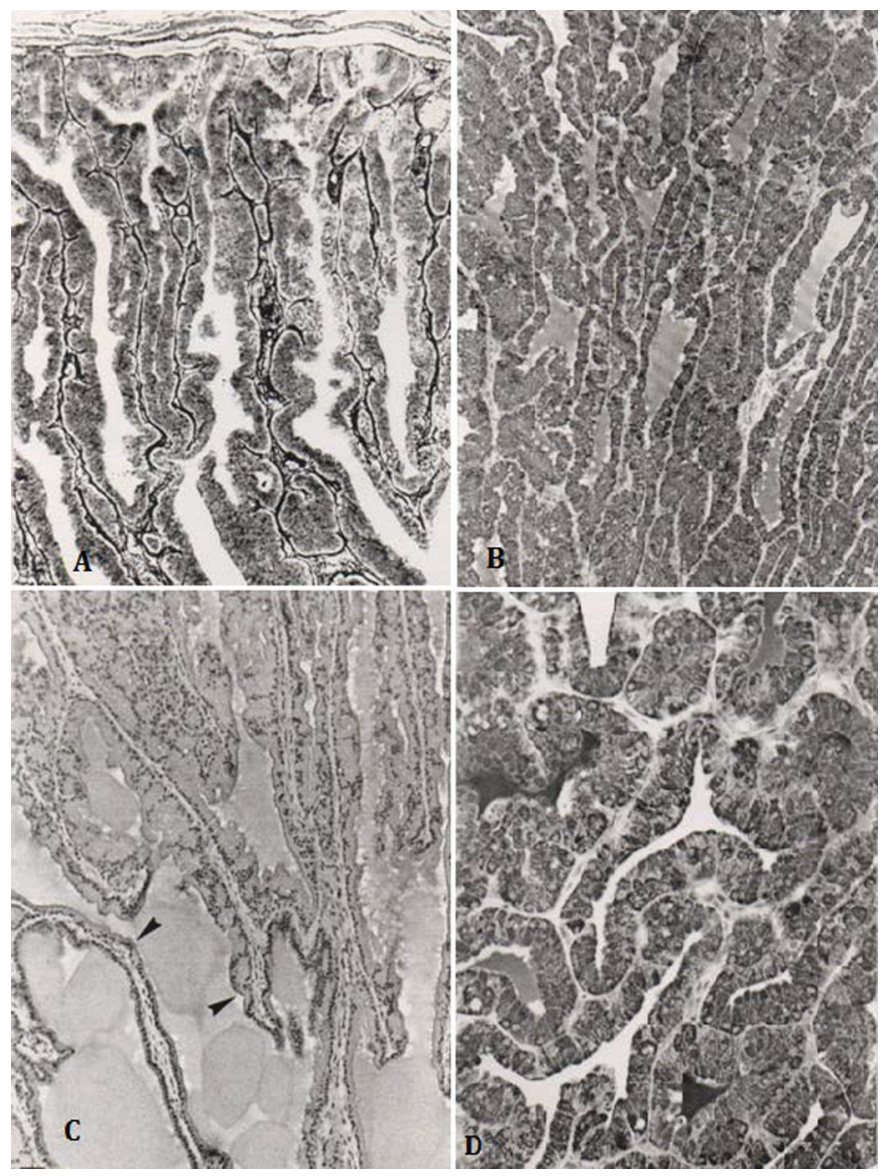

Fig.8. Glândula bulbouretral medial. (A) Observar a distribuição das fibras reticulares ao redor dos túbulos glandulares. Impregnação argêntica de Gomori, 76x. (B) Túbulos glandulares mostrando reação PAS positiva no epitélio e na secreção acumulada no lume. PAS, 76x. (C) A figura mostra a confluência dos túbulos secretores para formar os ductos coletores repletos de secreção. As cabeças de setas indicam a modificação epitelial nestas regiões. HE, 76x. (D) Epitélio secretor mostrando as granulações PAS positivas no citoplasma. PAS, 192x.

cados, revestidos por epitélio simples característico para cada par de glândulas.

O parênquima da glândula BUL é constituído por túbulos secretores longos, com lume e dilatado pela secreção acumulada (Fig.6A,B). 0 epitélio secretor é do tipo cúbico a pavimentoso. As células são moderadamente PAS positivas e amilase resistentes. Pela Ninhidrina-Schiff a reação foi moderada e tornou-se negativa após o bloqueio pelo ácido nitroso. A alcianofilia é negativa (Quadro 1). A secreção contida no lume apresenta-se homogênea, acidófila, fortemente PAS positiva (Fig.6B), amilase-resistente. A reação da Ninhidrina-Schiff foi negativa após o bloqueio pelo ácido nitroso. As glândulas bulbouretrais laterais produzem mucossubstâncias neutras. Os ductos se reúnem em um ducto único na parte afilada da glândula, caminhando em direção à uretra peniana. Esse ducto é revestido por epitélio cuboidal.

A BUI é constituída por glândulas tubulosas e ramificadas. À medida que convergem para formar o ducto principal, elas formam espaços coletores repletos de secreção 
(Fig.7A,B,D). 0 epitélio secretor é simples colunar, e as células apresentam citoplasma basófilo e vacuolado. A secreção armazenada no lume apresenta uma parte amorfa predominante e uma globular acidófila. As células epiteliais são fortemente PAS positivas e amilase-resistente. A alcianofilia $\mathrm{AB} \mathrm{pH}$ 2,5 é fortemente positiva, enquanto em $\mathrm{pH}$ 1,0 é moderada. Para AB 2,5 seguido de PAS, as células adquiriram tonalidade violeta. A fraca reação da Ninhidrina-Schiff tornou-se negativa após a reação de bloqueio (Quadro 1). A secreção contida no lume apresenta uma parte amorfa predominante, uma na forma de glóbulos e uma filamentosa. As partes amorfa e filamentosa, quando coradas pelo $\mathrm{AB} \mathrm{pH}$ 2,5, seguido de PAS, apresentam coloração violeta (Fig.7D); ao passo que os glóbulos são apenas PAS positivos. As partes amorfa e globular apresentam-se fracamente coradas pela Ninhidrina-Schiff e tornaram-se negativas após o bloqueio pelo ácido nitroso. A secreção produzida pela glândula é formada por mucossubstâncias neutras, ácidas carboxiladas e ácidas sulfatadas.

A glândula BUM é formada por longos túbulo-ácinos ramificados, que confluem para formarem os ductos coletores. 0 epitélio secretor é simples colunar, tornando-se cúbico ao nível dos ductos coletores (Fig.8C). 0 citoplasma apresenta-se acidófilo com granulações grosseiras concentradas principalmente na borda apical. A secreção no lume apresenta-se homogênea e acidófila. As células apresentam granulações grosseiras citoplasmáticas coradas pelo PAS (Fig.8B,D), que permaneceram positivas após o tratamento com amilase salivar. Esse material citoplasmático também apresentou reação positiva para Ninhidrina-Schiff. A secreção contida no lume é Ninhidrina-Schiff e PAS positivas, amilase-resistente. A alcianofilia é negativa (Quadro1). As glândulas bulbouretrais mediais secretam mucossubstâncias neutras.

\section{DISCUSSÃO}

Similarmente ao que ocorre na maioria dos marsupiais, as glândulas sexuais acessórias de Metachirus são a próstata e as glândulas bulbouretrais (Rodger \& Hughes 1973, Setchell 1977, Temple-Smith 1984; Tyndale-Biscoe \& Renfree 1987, Dawson et al. 1988, Ribeiro \& Nogueira 1982, Nogueira 1989, Martinelli 1990, Costa et al. 1994, Costa 1995, 1996, Barros et al. 2003, Cruz et al. 2011a, 2011b, Nogueira 2012, Lima et al. 2013).

A próstata de $M$. nudicaudatus apresenta uma forma de "ponto de interrogação" diferente do observado nos didelphidae já estudados. O formato de "cenoura" parece ser o predominante nas espécies americanas (Setchell 1977, Martan 1983, Garcia \& Gonçalves 1984, Dawson et al. 1988, Nogueira 1988, Martinelli 1990, Barros et al. 2003 na família Didelphidae), entretanto, uma espécie da família Caenolestidae (C. obscurus) apresenta a próstata em forma de coração (Setchell 1977, Tyndale-Biscoe \& Renfree 1987, Dawson et al. 1988). De acordo com Rodger \& Hughes (1973), Temple-Smith (1984) e Dawson et al. (1988), a próstata com forma de coração também está presente em marsupiais australianos.

Em M. nudicaudatus, a próstata apresenta três segmentos distintos em cor e tamanho, ao longo do seu compri- mento. 0 segmento cranial apresenta coloração rósea, o médio côr branco-leitosa e o caudal cinza. De acordo com a terminologia proposta por Nogueira et al. (1985) e Nogueira (2012), esses segmentos correspondem aos segmentos cranial, médio e caudal. A presença de três segmentos distintos também é descrita em outras espécies americanas: M. robinsoni (Barnes 1977); P. opossum (Ribeiro \& Nogueira 1982), D. albiventris (Garcia \& Gonçalves 1984, Nogueira 1988, Nogueira 2012); D. virginiana (Chase 1939, Eckstein \& Zuckerman 1956, Martan 1983); M. cinerea (Martinelli 1990, Martinelli et al. 1991) e G. microtarsus (Lima et al. 2013). Porém, de acordo com Rodger\& Hughes (1973), quatro tipos de segmentação da próstata podem ser descritos em algumas espécies australianas. Com relação à coloração dos diferentes segmentos prostáticos de M. nudicaudatus, observa-se similaridade ao descrito em P. opossum (Ribeiro \& Nogueira 1982), D. albiventris (Nogueira 1988) e M. nudicaudatus (Cruz et al. 2011), porém diferente do descrito por Martinelli (1990) e Martinelli et al. (1991) em M. cinerea, cujo segmento cranial apresenta tonalidade cinza.

O parênquima prostático em Metachirus nudicaudatus é constituído por glândulas tubulares compostas, disseminadas na mucosa uretral, semelhante ao descrito por vários autores em outras espécies de marsupiais (Fordham 1928 em Myrmecobius fasciatus, Chase 1939 em D. virginiana, Rodger \& Hughes 1973 em oito espécies de marsupiais australianos, Barbour 1977 em Lasiorhinus latifrons, Ribeiro 1981 em P. opossum, Martan 1983 em D. marsupialis,Temple-Smith 1984 em espécies australianas, Woolley \& Scarlett 1984 em Tarsipes rostratus, Garcia \& Goncalves 1984 em D. azarae, Tyndale-Biscoe \& Renfree 1987 em espécies australianas, Temple-Smith \& Taggart 1990 em Phascolarctos cinerus, Martinelli, 1990 em M. cinerea, Costa et al. 1996 em Metachirus nudicaudatus, Cruz et al. 2011a em Metachirus nudicaudatus e Lima et al. 2013 em G. microtarsus). A divisão dos túbulos secretores em partes externa, média e interna em $M$. nudicaudatus também é feita em outras espécies de Didelphidae, sendo que as características epiteliais das diversas partes dos segmentos prostáticos diferem na altura das células epiteliais, desenvolvimento de suas projeções apicais, diâmetro do lume e aspectos tintoriais das células (Nogueira et al. 1985 em P. opossum, Garcia \& Gonçalves 1984 em D. albiventris, Hardin 1967 em D. virginiana, Martinelli et al. 1991 em M. cinerea).

As células epiteliais do segmento cranial em $M$. nudicaudatus contêm mucossubstâncias neutras. Essas mucossubstâncias também foram observadas no lume dos túbulos e ductos glandulares. Em P. opossum (Nogueira et al. 1985) foram detectados nesse segmento glicogênio, sialomucinas e mucossubstâncias neutras, sendo que somente as duas últimas substâncias foram encontradas no lume glandular. Em M. cinerea (Martinelli et al. 1991), as células desse segmento contêm mucossubstâncias neutras, sendo que glicogênio também pode ser detectado nas células da parte externa. Todas essas substâncias também foram observadas no lume dos túbulos e ductos. De acordo com Setchell (1977) e Martan (1983), em D. virginiana as células do segmento cranial contêm mucossubstâncias, 
fosfolipídios, fosfatase ácida, aliesterase, 5' nucleotidase, nucleosídio-di-fosfatase e ainda ferro (Hruban et al. 1965, Martan 1983). Esse ultimo, possivelmente, é o responsável pela coloração escura desse segmento e a regulação da atividade enzimática do líquido seminal.

Foram evidenciados pelos métodos histoquímicos dois tipos celulares na parte externa do segmento médio de $M$. nudicaudatus, assemelhando-se ao observado em $M$. cinerea (Martinelli et al. 1991). Em M. nudicaudatus, os dois tipos celulares continham mucossubstâncias neutras, porém, em $M$. cinerea, um tipo apresentava mucossubstâncias neutras e sialomucinas e o outro tipo apenas mucossubstâncias neutras. Os dois tipos celulares presentes na parte média desse segmento prostático em Metachirus, apresentaram as mesmas reações, porém com diferenças em relação ao aspecto e a intensidade da reação. Com base nesses resultados histoquímicos, pode-se demonstrar a presença de mucossubstâncias neutras nessas células. Em M. cinerea (Martinelli et al.1991) o único tipo celular da parte média produz mucossubstâncias neutras e sialomucinas. Os dois tipos de granulações nas células da parte interna desse segmento em M. nudicaudatus são mucossubstâncias neutras. Em M. cinerea (Martinelli et al.1991) as células da parte interna contêm somente mucossubstâncias neutras. De acordo com Nogueira et al. (1985), o segmento médio da próstata do $P$. opossum possui dois tipos celulares que apresentam intensidades de reação diferentes aos métodos histoquímicos. As células desse segmento contêm glicogênio, mucossubstâncias neutras e sialomucinas, porém o glicogênio só foi detectado nas células da parte externa e interna. Segundo alguns autores (Hruban et al. 1965, Martan\& Allen 1965, Martan 1983), em D. virginiana, grânulos esféricos nas células do tipo A contêm mucossubstâncias ácidas, enquanto grânulos alongados das células tipo B contêm proteínas. Ladman \& Soper (1963) também detectaram nessa espécie a presença de grânulos esféricos e alongados contendo glicoproteínas e fosfolipídios na parte externa desse segmento.

As células epiteliais da parte externa do segmento caudal de Metachirus são acidófilas, porém apresentam um aspecto finamente vacuolado. A presença de células pouco coradas também foi observada em $D$. virginiana (Chase 1939) e na parte externa do segmento caudal de M. cinerea (Martinelli et al. 1991). De acordo com Hardin (1967) e Martan\& Allen (1965), em D. virginiana isso pode ser atribuído à pequena quantidade de organelas existentes nas células dessa região ou seria devido à distribuição periférica das organelas ou à presença de glicogênio no interior das células. No M. nudicaudatus na região de transição entre a parte externa e média, o epitélio apresenta células com vacúolos maiores ou, às vezes, único formando uma faixa em toda a sua extensão. Com relação aos testes histoquímicos realizados na parte externa desse segmento em M. nudicaudatus, suas células contêm glicogênio e pequena quantidade de mucossubstâncias neutras. Esse glicogênio também foi detectado na região de transição entre partes externa e média. As células epiteliais das partes média e interna produzem mucossubstâncias neutras. Em M. cinerea, Martinelli et al. (1991) detectaram glicogênio e pequena quantidade de proteínas nas células e no lume da parte externa, enquanto na parte média e porção inicial da parte interna observaram mucossubstâncias neutras. Nogueira et al. (1985) encontraram mucossubstâncias neutras no epitélio e no lume do segmento caudal do P. opossum, sendo que o glicogênio foi detectado apenas na parte externa e média desse segmento. Em D. albiventris (Garcia \& Gonçalves 1984) evidenciaram glicogênio na parte externa desse segmento caudal. Em Marmosa sp., P. opossum e C. derbianus (Martan 1983), o glicogênio foi demonstrado nas células de todo o segmento caudal.

Devido às diferenças de segmentação da próstata entre marsupiais americanos e australianos (Rodger \& Hughes 1973, Dawson et al. 1988), tornou-se difícil comparar os segmentos prostáticos entre os dois grupos. De acordo com Rodger \& Hughes (1973) e Temple-Smith (1984), mucossubstâncias neutras ou ácidas são os principais tipos de secreção prostática em espécies australianas. Lípides e proteínas também contribuem em pequenas quantidades.

A composição glicídica do plasma seminal difere entre mamíferos marsupiais e eutérios. Em eutérios, o principal glicídio é a frutose (Rodger 1976). Com relação à composição bioquímica do plasma seminal, constituído principalmente pela secreção prostática, existem diferenças na composição de açúcares do sêmen, entre marsupiais australianos e americanos (Martan 1983). Segundo Rodger \& Hughes (1973), Rodger \& White (1980), Temple-Smith (1984) e Dawson et al. (1988) a n-acetil-glicosamina e a glicose são os principais carboidratos do sêmen em várias espécies de marsupiais australianos. Em marsupiais americanos da família Didelphidae, o glicogênio parece ser o açúcar mais importante da próstata (Hruban et al. 1965, Martan \& Allen 1965, Rodger\& White 1980, Nogueira et al. 1985, Tyndale-Biscoe \& Renfree 1987, Dawson et al. 1988). Cóser \& Nogueira (1998) determinaram os níveis de glicogênio, frutose e ácido cítrico na próstata do $D$. albiventris, durante os períodos de não acasalamento e acasalamento. A concentração de ácido cítrico nos segmentos médio e caudal não variou nos diferentes períodos. Entretanto, as concentrações de frutose e glicogênio no segmento caudal foram maiores no período de acasalamento, sugerindo uma atividade secretora sazonal.

A inexistência de dados bioquímicos sobre a secreção prostática do $M$. nudicaudatus sugere a investigação desses parâmetros, bem como a verificação se esta glândula, à semelhança de outros marsupiais, tem uma atividade secretória sazonal. Observações ultra-estruturais do epitélio prostático e análise bioquímica de suas secreções tornam-se importantes para verificar se o glicogênio é de fato o elemento energético mais importante produzido pela glândula em outras espécies de Didelphidae, à semelhança do que ocorre em $D$. virginiana (Rodger \& White 1980).

M. nudicaudatus apresenta três pares de glândulas bulbouretrais que se assemelham aos aspectos histológicos observados em outros marsupiais, sendo que o seu epitélio secretor distingue-se de outras espécies, incluindo as da família Didelphidae, pela altura, morfologia citoplasmática e características tintoriais das células epiteliais. Em marsupiais americanos existem dois ou três pares de glândulas 
bulbouretrais denominadas glândulas bulbouretrais laterais, intermédias e mediais,nomes que se referem às suas posições anatomotopográficas (Nogueira et al., 1984). Na maioria das espécies estudadas existem três pares (Chase 1939, Ribeiro \& Nogueira 1982, Martan 1983, Dawson et al. 1988, Nogueira 1988, Martinelli 1990, Martinelli et al. 1991, Costa et al. 1996, Cruz et al. 2011b, Lima et al. 2013), ao passo que em Chironectes minimus existem somente dois pares de glândulas (Nogueira 2004) semelhante ao observado em marsupiais pertencentes aos gêneros Caluromys, Gracilinanus, Monodelphis, Thylamis, e Glironia.De acordo com Rodger \& Hughes (1973), Setchell (1977), Temple-Smith (1984), Tyndale-Biscoe \& Renfree (1987), Dawson et al. (1988), um a três pares de glândulas bulbouretrais podem ocorrer em marsupiais australianos.

As glândulas bulbouretrais de M. nudicaudatus secretam mucossubstâncias neutras, similarmente ao observado em P. opossum (Nogueira et al. 1984), em Metachirus nudicaudatus (Costa, 1995), em M. cinerea (Martinelli et al. 1991) e em Caluromys lanatus (Carvalho 1996). Mucossubstâncias ácidas carboxiladas foram detectadas na bulbouretral intermédia de Metachirus, embora pequena quantidade de sulfomucina também faça parte da secreção dessa glândula. A presença de mucossubstâncias, sialomucina e sulfomucinas na secreção das bulbouretrais é descrita em várias espécies da família Didelphidae, havendo diferenças em relação aos pares que secretam tais substâncias (Martan 1983, Ribeiro \& Nogueira 1985, Martinelli et al. 1991). A presença de glicogênio é ainda descrita nas bulbouretrais laterais e intermédias de $P$. opossum, porém esta substância só foi evidenciada no epitélio dos túbulos secretores e não no lume glandular (Nogueira et al. 1984). Em D. albiventris, Nogueira \& Redins (1989) demonstraram ultra-estruralmente partículas de glicogênio na BUI e BUM, sendo que nessa última foi em grande quantidade.

Em marsupiais australianos as secreções das glândulas bulbouretrais podem ser constituídas por mucossubstâncias neutras e ácidas, proteínas e lipídios (Rodger \& Hughes 1973, Barbour 1977, Temple-Smith 1984).

A presença de dois ou três pares de glândulas bulbouretrais nos marsupiais americanos e a composição complexa de suas secreções sugere papel importante dessas glândulas na fisiologia reprodutiva desses animais, além de simples função lubrificadora da uretra antes da ejaculação. (Rodger \& Hughes 1973, Temple-Smith 1984, Dawson et al. 1988). Para isso, estudos morfofuncionais e bioquímicos mais acurados deverão ser feitos para esclarecer a composição das secreções dessas glândulas e, se as secreções dessas glândulas são eliminadas em conjunto ou individualmente, bem como se antes, junto ou depois da fração espermática do sêmen.

\section{CONCLUSÕES}

As glândulas sexuais acessórias de Metachirus nudicaudatus se assemelham pelos aspectos morfológicos às de outras espécies de marsupiais americanos, incluindo as da família Didelphidae.

A presença de mucossubstâncias neutras e glicogênio na secreção prostática de Metachirus é registrada em outras espécies de marsupiais da família Didelphidae, havendo diferenças com relação ao local de produção destas substâncias.

A inexistência de dados ultra-estruturais do epitélio prostático e análises bioquímicas da secreção prostática de M. nudicaudatus sugere a investigação desses parâmetros para verificar se o glicogênio é de fato o elemento energético mais importante produzido pela glândula, bem como a verificação se esta glândula, à semelhança de outros marsupiais, tem uma atividade secretória sazonal.

A presença de três pares de glândulas bulbouretrais e a composição complexa de suas secreções (mucossubstâncias neutras, ácidas carboxiladas e ácidas sulfatadas) em Metachirus e em grande número de espécies de marsupiais americanos já estudados sugere que essas glândulas exercem outras funções na fisiologia reprodutiva desses animais, além da de lubrificação.

Agradecimentos.- Os autores agradecem à FAPEMIG (CVZ PPM-00359/ 14), Capes e CNPq (processo número 305478/2015-0) pelo apoio financeiro à pesquisa.

\section{REFERÊNCIAS}

Barbour R.A. 1977. Anatomy of marsupials, p.237-242. In: Stonehouse B. \& Gilmore D. (Eds), The Biology of Marsupials. Vol.15. MacMillan Press, London.

Barnes R.D. 1977. Reproductive system, p.404-412. In: Ibid. (Ed.), The Special Anatomy of Marmosa robinsoni. Vol.7. Academic Press, New York.

Barros M.A., Miglino M.A., Martins J.P., Ambrosio C.E., Verechia F.T., Rosa R.A. \& Carvalho A.F. 2003. Morfologia do sistema reprodutor masculino do gambá (Didelphis sp.). Revta Bras. Reprod. Anim. 27:225-226.

Carvalho G.A. 1996. Aspectos morfológicos do sistema genital masculino de Caluromys lanatus (Olfers, 1818) e Caluromys philander (Linnaeus, 1758) - Didelphidae - Marsupialia. Dissertação de Mestrado em Morfologia, Instituto de Ciências Biológicas, UFMG, Belo Horizonte. 117p.

Chase E.B. 1939. The reproductive system of the male opossum, Didelphis virginiana Kerr, and its experimental modification. J. Morphol. 65:215239.

Chiarini-Garcia H. 1991. Inclusão de material biológico em resinas plásticas. Departamento de Morfologia, Instituto de Ciências Biológicas, UFMG, Belo Horizonte. 21p.

Cóser A.M.L. \& Nogueira J.C. 1998. Glycogen, fructose and citric acid levels in the prostate of the white-belly opossum Didelphis albiventris (Marsupialia), during mating and non-mating periods. Braz. J. Vet. Anim. Sci. 50:695-698.

Costa S.F. 1995. Morfologia do sistema genital masculino de Metachirus nudicaudatus (Geoffrow, 1803), Didelphilidae, Marsupualia. Dissertação de Mestrado em Morfologia, Instituto de Ciências Biológicas, Universidade Federal de Minas Gerais, Belo Horizonte, MG. 128p.

Costa S.F., José H. \& Nogueira J.C. 1996. Aspectos anatômicos do sistema genital masculino do jupati, Metachirus nudicaudatus. Bios 4:31-36.

Costa S.F., José H. \& Nogueira J.C. 1994. Morfologia do sistema genital masculino de Metachirus nudicaudatus, Didelphidae-Marsupialia. Anais Reunião da Sociedade Brasileira para o Progresso da Ciência, Vitória, p.761. (Resumo)

Costa S.F., Nogueira J.C., Soares B.A., Ambrósio N.A., Chaves A.S., Melo L.Q. \& Zangeronimo M.G. 2015. Morfologia do escroto, do testículo e das vias espermáticas de Metachirus nudicaudatus (Geoffroy, 1803), Didelphidae-Marsupialia. Pesq. Vet. Bras. 35(Supl.1):69-83.

Cruz M.S., Barbosa F.O., Santos R.C., Costa S.F., Teófilo T.S. \& Nogueira J.C. 2011a. Morfologia da glândula Prostática do Jupati (Metachirus nudicaudatus). Anais $24^{\circ}$ Congresso de Iniciação Científica da UFLA, Lavras, p.462. (Resumo) 
Cruz M., Barbosa F.O., Santos R.C., Costa S.F., Teófilo T.S. \& Nogueira J.C. 2011b. Análise Histológica das Glândulas Bulbo-Uretrais do Jupati (Metachirus nudicaudatus). Anais $24^{\circ}$ Congresso de Iniciação Científica da UFLA, Lavras, p.592. (Resumo)

Cowper W. 1704. Giving an account of the anatomy of those parts of a male opossum that differ from the female. Philosophic. Transact. Royal Soc. London B, Biol. Sci. 24:1576-1590.

Dawson T.J., Finch E., Freedman L., Hume I.D., Renfree M.R. \& Temple-Smith P.D. 1988. Morphology and physiology of the metatheria. Fauna of Australia 1:17.

Eckstein P. \& Zuckerman S. 1956. Morphology of the reproductive tract, p.46-65. In: Parkes A.S. (Ed.), Marshall's Physiology of Reproduction. Vol.1. pt. 1. Longman Green, London.

Fordham M.G.C. 1928. The anatomy of the urinogenital organs of the male Myrmecobius fasciatus. J. Morphol., 46: 563-583.

Garcia P.J. \& Gonçalves R.P. 1984. Observações morfológicas da próstata do gambá (Didelphis azarae). Revta Bras. Ciênc. Morfol. 1:17-23.

Gardner A.L. 1993. Order Didelphimorphia, Paucituberculata and Microbiotheria, p.15-23. In: Wilson D.M. \& Reeder D.E. (Eds), Mammals Species of the World. 2nd ed. Smithsonian Institution Press, Washington.

Gomori G. 1937. Silver impregnation of reticulum in paraffin sections. Am. J. Pathol. 13:993.

Hardin J.H. 1967. A cytological and cytochemical study or the third part of the prostate gland of the opossum Didelphis marsupialis. Dissertation Abstracts 27:4217-4219.

Hruban Z., Martan J., Slesers A., Steiner D.F., Lubran M. \& Rechcigl Jr. M. 1965. Fine structure of the prostatic epithelium or the opossum (Didelphis virginiana Kerr). J. Exp. Zool. 160:81-105.

Ladman A.J. \& Soper E.H. 1963. Cytological observations on intragranular inclusion bodies in the prostate of the opossum. Anat. Rec. 145:364.

Lev R. \& Spicer S.S. 1964. Specific staining of sulphate groups with Alcian Blue at low pH. J. Histochem. Cytochem. 12:309.

Lillie R.D. 1958. Acetylation and nitrosation of tissue amines in histochemistry. J. Histochem. Cytochem. 6:352-361.

Lillie R.D. \& Fullmer H.M. 1976. Histopathologic technic and practical histochemistry. 4th ed. McGraw Hill, New York.

Lima J.M.N., Santos A.C., Viana D.G., Bertassli B.M., Lobo L.M., Oliveira V.C., Briani D.C., Costa G.M., Assis Neto A.C.A., Ambrosio C.A., Carvalho A.F. \& Mançanares C.A.F. 2013. Morphological study of the male genital organs of Gracilinanus microtarsus. Braz. J. Vet. Res. Anim. Sci. 50:447-456.

Lison L. 1960. Histochimie at cytochimie animals: principes et methods. $3^{\text {ième }}$ ed. Gauthier-Villars, Paris.

Luna L.G. 1968. Manual of histologic staining methods of the armed forces institute of pathology. 3rd ed. McGraw-Hill, New York.

Martan J. 1983. The genital tract of the male opossum Didelphis marsupialis virginiana and other marsupials. Trans. I11, State Academic Sciences 76:3-28.

Martan J. \& Allen J.M. 1965. The cytological and chemical organization of the prostatic epithelium of Didelphis virginiana Kerr. J. Exp. Zool. 159:209-229.

Martinelli P.M. 1990. Morfologia do sistema genital masculino de Marmosa cinerea Temminck, 1824 (Didelphidae-Marsupialia). Dissertação de Mestrado em Morfologia, Instituto de Ciências Biológicas, Universidade Federal de Minas Gerias, Belo Horizonte, MG. 141p.

Martinelli P.M., Nogueira J.C. \& Campos P.A. 1991. Morphology, glucogen and mucosubstances histochemistry of the prostate and bulbo-urethral glands of the Marmosa cinerea Temminck, 1824 (Marsupialia-Didelphidae). Revta Bras. Ciênc. Morfol. 7:3-11.

McManus J.F.A. 1946. Histological demonstration of mucin after periodic acid. Nature 158:202.

Mowry R.W. 1956. Alcian Blue technique for the histochemical study of acidic carbohydrates. J. Histochem. Cytochem. 4:407.

Nogueira J.C. 1988. Anatomical aspects and biometry of the male genital system of the White-belly opossum. Didelphis albiventris Lund, $1841 \mathrm{du}-$ ring the annual reproductive cycle. Mammalia 52:233-242.

Nogueira J.C. 2012. Morfologia do sistema genital masculino de marsupiais brasileiros, p.217-244. In: Cáceres N.C. (Ed.), Os Marsupiais do Brasil: biologia, ecologia e conservação. $2^{\underline{a}}$ ed. Editora UFMS, Campo Grande, MS.

Nogueira J.C. \& Ribeiro R.D. 1980. A simplified Weigert's method for staining elastic fiber. Arqs Esc. Vet. UFMG 1:333-335.

Nogueira J.C., Campos P.A. \& Ribeiro M.G. 1984. Histology, glycogen and mucosubstance histochemistry of the bulbourethral glands of the Philander opossum Linnaeus, 1758. Anat. Anz. 156:321-328.

Nogueira J.C., Ribeiro M.G. \& Campos P.A. 1985. Histology and carbohydrate histochemistry of the prostate gland of the Brazilian four-eyed opossum (Philander opossum Linnaeus, 1758). Anat. Anz. 159:241-252.

Nogueira J.C. \& Redins C.A. 1989. Modificações sazonais na ultra-estrutura das glândulas bulbo-uretrais do gambá Didelphis albiventris (Marsupialia). Anais $12^{\circ}$ Colóquio da Sociedade Brasileira de Microscopia Eletrônica, Caxambu, 1:163-164.

Nogueira J.C., Castro C.S.A., Câmara E.V.C. \& Câmara B.G.O. 2004. Morphology of the male genital system of Chironectes minimus and comparison to other didelphid marsupials. J. Mammalogy 85:834-841.

Renfree M.B. 1981. Marsupials: alternative mammals. Nature 293:100101.

Ribeiro M.G. 1981. Aspectos anatômicos e histologia do sistema genital masculino da cuíca Philander opossum (Linnaeus, 1758) Didelphidae Marsupialia. Dissertação de Mestrado em Morfologia, Instituto de Ciências Biológicas, UFMG, Belo Horizonte. 147p.

Ribeiro M.G. \& Nogueira J.C. 1982. Aspectos anatômicos do sistema genital masculino da cuíca Philander opossum (Linnaeus, 1758), Didelphidae-Marsupialia. Lundiana 2:57-69.

Ribeiro M.G. \& Nogueira J.C. 1985. Histoquímica de mucossubstâncias nas glândulas bulbo-uretrais (Cowper) de alguns marsupiais brasileiros. Anais 37a Reunião da Sociedade Brasileira para o Progresso da Ciência, Belo Horizonte, p.664. (Resumo)

Rodger J.C. \& Hughes R.L. 1973. Studies of the accessory glands of male marsupials. Aust. J. Zool. 21:303-320.

Rodger J.C. 1976. Comparative aspects of the accessory sex glands and seminal biochemistry of mammals. Comp. Biochem. Physiol. 53(B):1-8.

Rodger J.C. \& White I.G. 1980. Glycogen not N-acethylglucosamine the prostatic carbohydrate of three Australian and American marsupials', and patterns of these sugars in Marsupialia. Comp. Biochem. Physiol. B 67:109-133.

Setchell B.P. 1977. Reproduction in male marsupials, p.411-457. In: Stonehouse B. \& Gilmore D. (Eds), The Biology of Marsupials. MacMillan Press, London.

Temple-Smith P.D. 1984. Reproductive structures and strategies in male opossums and gliders, p.89-106. In: Smith A.P. \& Hume I.D. (Eds), Possums and Gliders. Surrey Beaty and Sons, Sidney.

Temple-Smith P.D. \& Taggart D.A. 1990. On the generative organs of the Koala (Pharcolarctos cinereus): an update, p.33-54. In: Lee A.K., Handassyde K.A. \& Sanson G.D. (Eds), Biology of the Koala. Surrey Beatty and Sons, Sidney.

Tyndale-Biscoe C.H. 1973. Life of Marsupials. Edward Arnold, London.

Tyndale-Biscoe C.H. \& Renfree M. 1987. Male anatomy and spermatogenesis, p.124-171. In: Tyndale-Biscoe C.H. \& Renfree M. (Eds), Reproduction Physiology of Marsupials. Cambridge University Press, Cambridge.

Woolley P.A. \& Scarlett G. 1984. Observations on the reproductive anatomy of male Tarsipes rostratus (Marsupialia: Tarsipedidae), p.445-450. In: Smith A.P. \& Hume I.D. (Eds), Possums and Gliders. Surrey Beaty and Sons, Sidney.

Yasuma A. \& Ichikawa T. 1953. Ninhydrin-Schiff and Alloxcan-Schiff staining: a new histochemical staining method for protein. J. Lab. Clin. Med. 41:296-299. 